\title{
A ESPECIALIZAÇÃO E ADAPTAÇÃO DA FORÇA DE TRABALHO NA AGRICULTURA MODERNA
}

\author{
Maria Madalena Zocoller Borba *
}

\section{Introdução}

Os debates acadêmicos sobre as modernas tecnologias que vêm sendo utilizadas pela agricultura brasileira pós 60 , têm sido encaminhados no sentido de analisar. de modo mais enfático, as transformações capitalistas de base produtiva agrícola e das relações sociais de produção e trabalho com a modernização. Pouca atenção tem sido dada às alterações nos processos de trabalho e na qualificação da mão-de-obra rural, quando da adoção desse padrão tecnológico moderno.

Por outro lado existe o senso comum de que tecnologias modernas exigem uma população trabalhadora mais qualificada, mais instruída. Esse discurso está também presente na fala dos produtores rurais quando clamam por trabalhadores com um grau maior de qualificação e instrução para a agricultura e por políticas governamentais de qualificação da força de trabalho rural. No entanto, autores como SALM e BRAVERMANN, apontam para uma tendência oposta, ou seja, tcoricamente os avanços tecnológicos no capitalismo possibilitam maior divisão e especialização do trabalho de modo que o trabalho vai se tornando mais simples, o seu contcúdo empobrecido e daí a desqualificação da força de trabalho no processo.

SALM(1980) recuperando a análise marxista sobre o sentido do progresso tecnológico no capitalismo, pensa a adequação da mão-de-obra aos requerimentos do capital de forma a que o capital não cria obstáculos à sua valorização. Para ele, a história do mercado de trabalho é a história de como o capital vai se libertando dos entraves que o trabalho possa lhe trazer; é a história do controle do trabalho pelo capital. Assim sendo, coloca como instru- mento mais poderoso para adequar a mãode-obra no capitalismo, o empobrecimento da maioria dos cargos e funçõcs, ou seja. a desqualificação da força de trabalho que se apresenta como tendência geral do avanço capitalista.

BRAVERMANN(1981) também trata da degradação do trabalho no capitalismo monopolista. Segundo esse autor, o parcelamento das funções e a reconstrução da produção como um processo coletivo ou social, destruíram o conceito de qualificação (fundamentado no domínio do ofício) c inauguraram apenas um modo para $o$ domínio do processo de trabalho a ser feito mediante e com o conhecimento científico, técnico e de engenharia do trabalho. Com esses conhecimentos concentrados nas mãos da administração, fecha-se o seu acesso à população trabalhadora. Portanto, à medida que a ciência é cada vez mais incorporada ao processo de trabalho, o trabalhador cada vez menos compreende o processo. Deixa-se assim ao trabalhador um inadequado conceito de qualificação: "uma habilidade específica, uma operação limitada e repetitiva". A capacitação do trabalhador resume-se, portanto, a instruí-lo para executar as diretrizes de um programa de trabalho.

Tendo esse referencial geral, o presente texto procura analisar as transformações na base tćcnica da produção e observar seus efeitos qualitativos sobre a força de trabalho rural. Especialmente, examinase a especialização e a adaptação da força de trabalho no processo produtivo agricola. Para tanto utiliza-se informações da região paulista de Ribeirão Preto, conhecidamente uma das mais dinâmicas na adoção de modernas tecnologias de produção agrícola.

\section{A tecnologia e a especialização da força de trabalho agrícola}

O padrão capitalista de modernização da agricultura da região de Ribeirão Preto está assentado, fundamentalmente, numa tecnologia de produção utilizadora de insumos químicos. de mecanização, de sementes e variedades melhoradas e no emprego de trabalhadores assalariados. Esse tem implicado. nas últimas décadas, em alterações na organização da produção. nas relações de trabalho, na realização e organização do trabalho e no tipo de força de trabalho demandada pela agricultura.

A reestruturação constantc do processo produtivo regional, revela a transformação industrial dessa agricultura que ocorre através de apropriações parciais e descontínuas do trabalho rural, bem como dos processos biológicos de produção, pelo capital. Essa transformação representa a submissão das condições naturais de produção e do trabalho ao capital. Como parte desse processo geral de intensificação do controle do trabalho pelo capital, é entendida a especialização da força de trabalho rural. O trabalhador especializado perde o controle do processo de produção e de trabalho, passando a ser mero executor de uma parcela desses

O processo de trabalho é transformado pelo capital através da maior divisão do trabalho possibilitada pelos avanços tecnológicos. Essa divisão vem ocorrendo em condições de expansão, da escala de produção, juntamente com elevado grau de especialização da estrutura produtiva em termos de serviços prestados pelos setores de apoio à produção, das máquinas, 
equipamentos e insumos utilizados e da força de trabalho envolvida nessa estrutura.

A moderna base tecnológica de produção agrícola regional está ligada a processos de trabalho que, por um lado, ocupam trabalhadores com maior grau de especialização cujas qualificações advêm de tecnologias "fabricadas" pelo capital e, por outro, um grande contingente de trabalhadores que exercem trabalhos repetitivos que requerem apenas o uso da força-física no desempenho das tarefas produtivas.

A incorporação de máquinas ao processo produtivo agrícola, conduz à utilização de trabalho especializado como o de tratorista, o qual tem como função na produção estar a serviço da máquina. Desenvolvendo habilidades para conduzir a máquina ele se adapta a ela e se especializa na sua operação, perdendo o controle do processo de trabalho e de produção. Esse tipo de inovação tecnológica coloca o trabalho a serviço do capital.

As inovações químicas, como o uso de herbicidas, também têm efeitos sobre o processo de trabalho e a especialização do trabalhador. A carpa manual perde espaço para a carpa química que normalmente está conjugada ao processo mecanizado. Deste modo, uma nova forma de realizar o trabalho se impõe com o uso desse insumo. Inclusive a maior adequação dessa técnica, tem passado por identificação das ervas daninhas visando o uso de produtos mais específicos e seletivos. Nesse caso há também a utilização de trabalhadores que são treinados na identificação e contagem das ervas daninhas.

O controle de pragas e doenças através do uso de insumos químicos e com base em levantamentos prévios do nível de infestação das lavouras, é outra inovação tecnológica que tem implicações na realização do trabalho e no emprego de trabalhadores especializiados. A identificação de pragas e doenças na lavoura e sua contagem para a determinação do momento exato do controle, são feitas por trabalhadores que adquirem no treinamento, habilidades específicas para desempenhar tal tarefa. Posteriormente, o tratamento fitossanitário da lavoura, ocorre também via sistema mecanizado substituindo o trabalho realizado de forma manual.

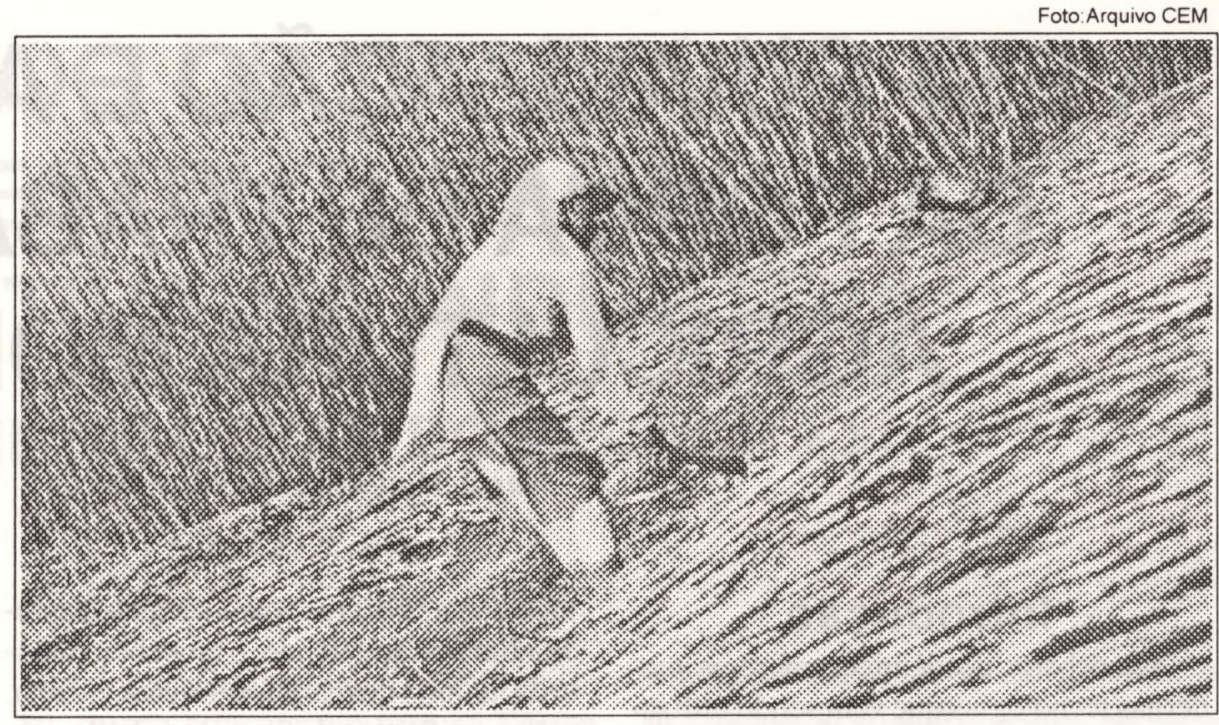

Foto: Arquivo CEM

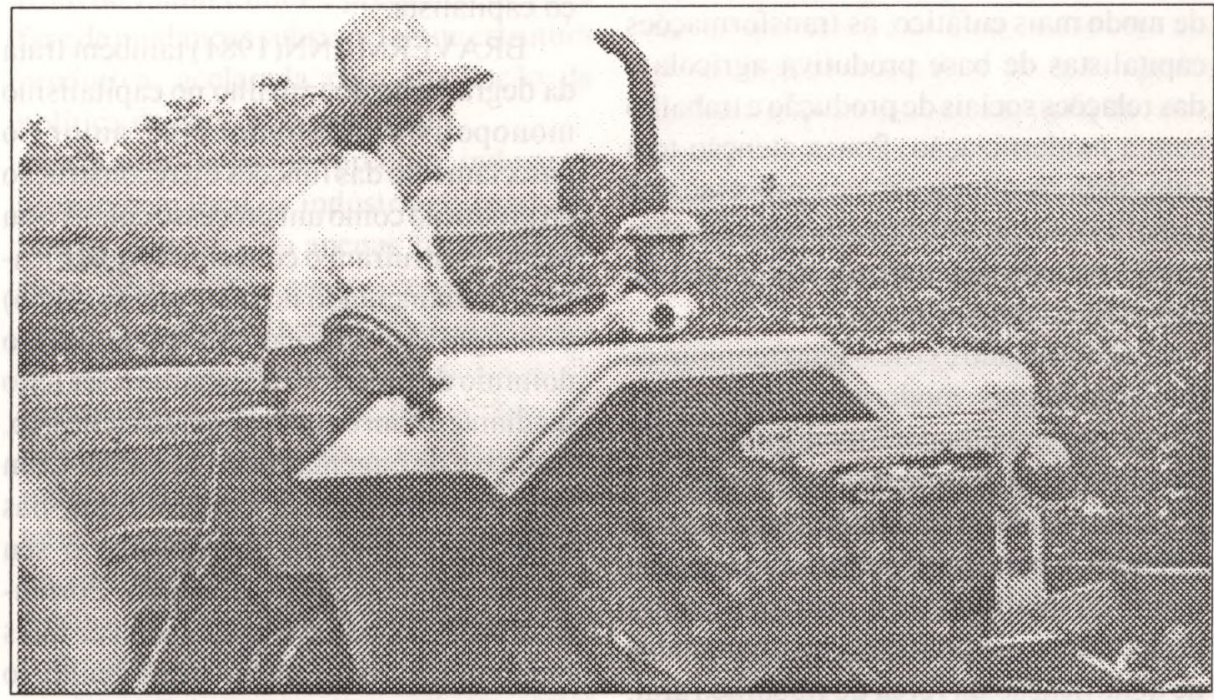

Foto Beto Estevam

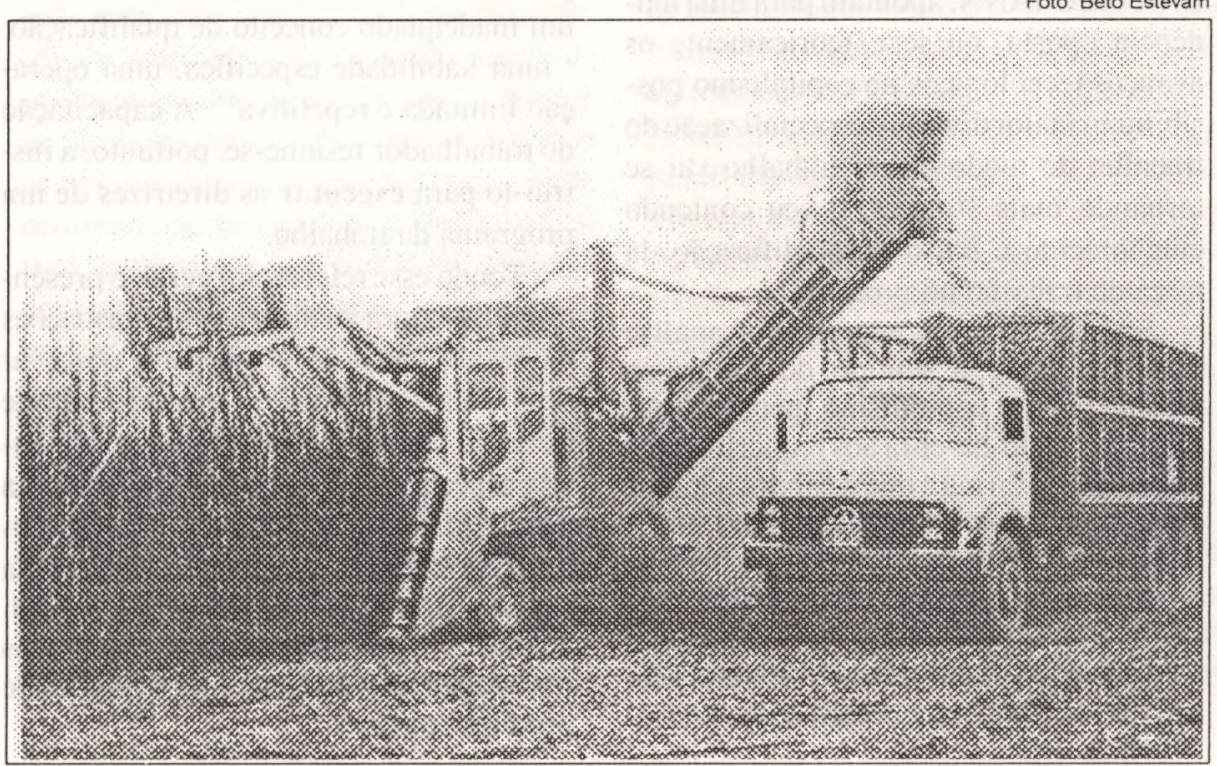


O controle biológico de pragas é outra técnica que utiliza trabalho com nível maior de especialização. Essa técnica envolve a identificação e contagem de praga ao nivel do campo, a reprodução $\mathrm{em}$ laboratórios dos inimigos naturais e distribuição desses nas plantações com problemas.

As inovações biológicas incorporadas aos processos produtivos agrícolas, como sementes e variedades melhoradas, constituem-se também em veículos de alteração do processo de trabalho e de emprego especializado na medida que têm permitido acelerar o uso de técnicas mecanizadas e da quimificação no processo de produção.

A informática aplicada à agricultura. também viabiliza a utilização de trabalho especializado no campo, afetando a organização e a realização do trabalho. Além dos trabalhadores diretamente envolvidos com a operação dos micros, o uso da informática possibilita na produção propriamente dita, a sistematização das tarefas diárias, o desenvolvimento de controle de produtividade e o emprego mais adequado de técnicas de produção.

\section{A especialização do trabalho rural}

Um indicativo da especialização do trabalhador no campo, é obtido do exame da evolução do número de operadores de máquinas ocorrida nas últimas décadas na região de Ribcirão Preto e no Estado de São Paulo. Pela análise de dados do Instituto de Economia Agrícola (IEA), é possível constatar uma evolução positiva do número de operadores de máquinas no período de 1971 a 1991, nessa agricultura tecnologicamente moderna. A região de Ribeirão Preto contava em 1971 com cerca de 4.211 operadores de máquinas residentes, número esse que cresceu para 6.332 em 1976, $8.477 \mathrm{em} 1980$ e $11.202 \mathrm{em}$ 1991. No Estado de São Paulo os números observados são: $14.026 \mathrm{em} \mathrm{1971;} 18.148$ em 1976; 23.805 em 1980; e $54.563 \mathrm{em}$ 1991. Esses dados, apesar de se referirem aos trabalhadores residentes, dão mostra da crescente absorção do trabalho especializado pela agricultura regional e do Estado.

Deve-se salientar que o número total de trabalhadores residentes na agricultura paulista e regional, tem decrescido nas últimas décadas. Em 1971 a região de Ribcirão Preto tinha cerca de 126.571 trabalhadores residentes e o Estado cerca de 1.323.092, de acordo com o IEA. Em 1980 o Estado contava com 717.423 trabalhadores residentes e a região em questão com 77.122. Em 1991, cxistiam cerca de 651.573 trabalhadores residentes no Estadoe 67.386 na região de Ribcirão Preto. Esse esvaziamento do campo que os dados indicam, é resultante do intenso processo de urbanização ocorrido no país, especialmente pós 60 , com a adoção de um modelo econômico de desenvolvimento industrializante e de uma modernização conservadora da agricultura. Em 1960 a região de Ribeirão Preto já era bastante urbanizada, pois cerca de $53,7 \%$ de sua população residia no mcio urbano. Essa porcentagem sobe bastante em 1970. sendo a população urbana $71.5 \%$ da população total e em 1980 , chega a $84.3 \%$.

Desta forma, pode-se inferir que os trabalhadores mantidos residentes, preferencialmente são aqueles com algum nível de especialização como é o caso dos tratoristas ou operadores de máquinas. Os operadores de máquinas na região, tiveram sua participação relativa elevada de $3 \%$ do total de trabalhadores residentes em 1971 , para $11 \% \mathrm{em} 1980$ e $16 \%$ aproximadamente em 1991. O exame dos dados em nível de Estado, indica uma participação menor desse tipo de trabalho: 1\% em 1971; $3 \% \mathrm{~cm} 1980$ e $8 \%$ do total de trabalhadores residentes em 1991.

Comparativamente ao Estado de São Paulo, a região de Ribcirão Preto se destaca como importante utilizadora de trabalho especializado.

A relação entre o número de operadores de máquinas residentes na região e no Estado, era de $30 \%$ em 1971. Pós 1971 , com a mecanização se expandindo $\mathrm{em}$ todas as etapas do processo produtivo agrícola e nas unidades de produção rural, cai a participação da região no número de operadores de máquinas residentes no Estado. Em 1991, a região ocupava $23 \%$ do número de operadores de máquinas residentes no Estado.

Saliente-se ainda que do final dos anos 80 ao início de 90 , o número de operadores de máquinas residentes na região ficou praticamente estável. O que se tem notado de modo geral na região, é que a mecanização já atingiu nível bastante elevado nas principais atividades agrícolas (cana. soja, milho, amendoim, laranja). Além disso, ela vem ocorrendo de acordo com padrão utilizador de máquinas com grande capacidade e eficiência operacional, fato esse que explica em parte, a estabilidade na utilização de operadores de máquinas na região.

Nas agroindústrias, particularmente a produção da cana-de-açúcar, é realizada com o crescente emprego de máquinas muito potentes, desde a conservação e preparo do solo, até a colheita. O corte mecanizado da cana, por exemplo, tem substituído a operação de carregamento mecânico quando o corte da cana ocorre de forma manual.

Deste modo, a região de Ribeirão Preto ao desenvolver uma agricultura altamente tecnificada, com elevado padrão de mecanização, vem alterando o perfil de absorção de mão-de-obra, aumentandoa utilização de trabalho especializado na realização da produção propriamente dita.

\section{Adaptação da força de trabalho}

A especialização crescente da força de trabalho nos segmentos mais modernos da agricultura, tem implicado na necessidade de treinamentos específicos dos trabalhadores. Esses são decorrentes dos avanços tecnológicos pelos quais passa a agricultura, principalmente no que diz respeito ao aperfeiçoamento das máquinas, equipamentos, tipos de insumos modernos e das técnicas agronômicas utilizadas na produção. Assim, por exemplo, os guincheiros da cana necessitam de treinamento para operar a carregadeira mecânica; os operadores de máquinas para execução da colheita mecanizada na cana e soja; os tratoristas para aplicação de herbicida; os contadores de pragas na identificação e contagem dos insetos que infestam as culturas como citrus e soja; os trabalhadores dos viveiros de mudas de cana ("roguistas") no conhecimento das variedades de cana, pragas e doenças, além de técnicas de tratamento térmico dos toletes 
para plantio. Esses trabalhadores são portanto treinados a conhecer as especificidades de uma técnica inserida no processo produtivo, perdendo o controle do processo como um todo.

A especialização chega a um ponto que na agroindústria da cana, por exemplo, os operadores de máquinas de pneus não são utilizados $\mathrm{em}$ operações que envolvem o uso de máquinas de esteira antes de passarem por treinamento. Destaca-se ainda o caso dos operadores de máquinas agrícolas, das agroindústrias da cana, que esses são treinados a conhecer o funcionamento da máquina, a ter conhecimento das operações agrícolas, a sabero tipo de implemento para cada máquina de modo a operá-la eficientemente. É exigido do operador que conduza a máquina sem causar avarias à mesma. O operador deve ser capaz de identificar irregularidades no funcionamento da máquina com a finalidade de acionar, no momento certo. a estrutura de apoio (por exemplo, oficina mecância móvel) disponível. Observa-se que o operador de máquina é um condutor eficiente e especializado em um tipo de máquina e mesmo em determinados tipos de operações agrícolas. Ele não é responsável nem pela regulagem da máquina e/ou equipamento nem pela manutenção dos mesmos, existindo para isso equipes montadas com tal finalidade.

Com a utilização da informática no gerenciamento da produção, vem sendo ainda exigido desse trabalhador um nivel de alfabetização para que tenha condições de preencher fichas de controle diário da máquina e das operações executadas.

$\mathrm{O}$ treinamento do trabalhador visando maior habilidade, destreza e conhecimento para a realização das operações de produção ocorre fundamentalmente ao longo do processo de trabalho. na execução das tarefas produtivas. Desta forma o processo de trabalho é também um processo de formação do trabalhador.

O treinamento dos trabalhadores agricolas dá-se sob a orientação dos funcionários mais antigos e habilitados. Os trabalhadores ingressantes vão adquirindo conhecimentos específicos pelo acompanhamento e repetição das tarefas mais simples no início e mais complexas no decorrer da aprendizagem. Para o caso específico dos tratoristas. $\mathrm{o}$ administrador ou o tratorista mais experiente assume o papel de monitor. repassando os conhecimentos aos aprendizes na forma de reuniões ou cursos informais na própria fazenda ${ }^{1}$.

O treinamento no trabalho tem, portanto, como característica a informalidade. Constitui-se num processo de aprendizagem que envolve habilidades especificas em condições de trabalho rotineiro, sujeito a costumes e regras informais formadas no próprio local de trabalho.

A característica da informalidade dificulta identificar com clareza, a natureza precisa deste processo de treinamento e as próprias qualidades particulares da força de trabalho requeridas pelo processo de produção. As dificuldades dos empresários em cxpressar de forma clara o que seja a formação de scu trabalhador, o conhecimento necessário a ser adquirido, é entendivel nesse contexto em que as habilidades são adquiridas no próprio desempenho do trabalho.

O trcinamento no trabalho assume um caráter automático, sendo um contínuo ajustamento de habilidades e transferência de conhecimentos dos trabalhadores experientes para os menos experientes no âmbito da produção. Nessas condições o processo de produção acaba por disciplinar a aprendizagem do trabalhador.

As habilidades especificas adquiridas no desenvolvimento das tarefas produtivas, conduzem para um não registro dessa experiência. Então o processo de aprendizagem necessita ser feito por transmissão direta de experiência. Os trabalhadores têm dificuldades de descrever e demonstrar as habilidades que possuem fora do contexto da produção. Deste modo, o treinamento é conduzido por demonstração e é aprendido apenas o que serve para a execução de uma tarefa.

Esse processo de treinamento acaba por se tornar um instrumento da estabilização das relações de emprego, encorajando os empresários a reduzir a rotatividade da mão-de-obra. $\mathrm{O}$ treinamento da força de trabalho é então assu- mido pela empresa e constitui-se tanto em mecanismo de promoção. quanto de manutenção do emprego do trabalhador. Especificamente nas agroindústrias, a possibilidade de promoção constitui-se na esteira rolante da formação profissional.

\section{Considerações Finais}

Reafirmando o que se procurou apresentar no decorrer do texto, a mudança na base técnica de produção agrícola, ocorrida nas últimas décadas, tem implicado na altcração do processo de trabalho no sentido da especialização e desqualificação da força de trabalho diretamente envolvida com a produção.

Essa agricultura tecnologicamente mais evoluída, dá mostras de uma organização do processo de trabalho em que estão presentes os princípios taylorista-fordista. $\mathrm{O}$ trabalhador da agricultura está se tornando especializado, desenvolvendo uma trabalho parcelizado e perdendo o controle do processo como um todo.

Pode-se inferir que a fase atual de desenvolvimento da agricultura, está muito mais para a ocorrência do paradigma taylorista-fordista, do que para a sua superação. Isso se dá na agricultura, diferentemente da tendência que se verifica no setor industrial onde as novas tecnologias apontam para uma superação de tal paradigma.

* Maria Madalena Zocoller Borba é Profa. do Dpto. de Economia RuraLUNESP-JaboticabalSP.

\section{NOTA}

1-Além desse tipo de treinamento, esses trabalhadores têm recebido esporadicamente cursos oferecidos pelas firmas e/ou concessionárias de máquinas e equipamentos agrícolas. Cooperativas e órgãos do setor público também oferecem cursos sobre o funcionamento e manutenção de equipamentos. Salientese ainda que para esses cursos são enviados principalmente administradores, tratoristas mais experientes - os trabalhadores que têm condições de acompanhar e assimilar as informações escritas e oralmente transmitidas.

\section{BIBLIOGRAFIA}

- BRAVERMANN, H. Trabalho e capital monopolista, a degradação do trabalho no século $X X$. Rio de Janeiro: Zahar, 1981, 379p.

- SALM, C. Escola e trabalho. Campinas: Instituto de Filosofia e Ciências Humanas, UNICAMP, 1980, 103p.

Tese (Doutorado) 